\section{A Bevelled Tube Slide on a Fiberoptic Gastroscope for Removal of a Dental Prosthesis from the Esophagus}

Cotton and Williams in 1990 described the use of a tube over the flexible endoscope to extract pointed objects, such as a safety pin. However, this may not be successful in extracting sharp foreign bodies whose width is greater than the diameter of the overtube. The bevelled sliding tube on a fiberoptic gastroscope can be used for nontraumatizing extraction of a foreign body from the esophagus or other hollow organs.

A middle-aged man was referred to us for removal of an artificial denture that had been swallowed. A protective overtube, bevelled for about $5 \mathrm{~cm}$ at the distal end was used. The denture was held grasped in a polypectomy snare (Figure 1) in such a way that the hooks of the denture were directed towards the advancing slide tube on the gastroscope (Figure 2), which was sandwiched between the esophageal wall and the hooks of the denture. The whole assembly was then withdrawn under direct vision without injuring the pharyngoesophageal wall.

Sharp and pointed foreign bodies in the esophagus are difficult to treat due to the inherent danger of injuring the esophagus during endoscopic extraction.

\section{S. P. Chouhan, H. K. Das Gupta}

Dept. of Surgery, S. P. Medical College and Associated Group of Hospitals, Bikaner, Rajasthan, India

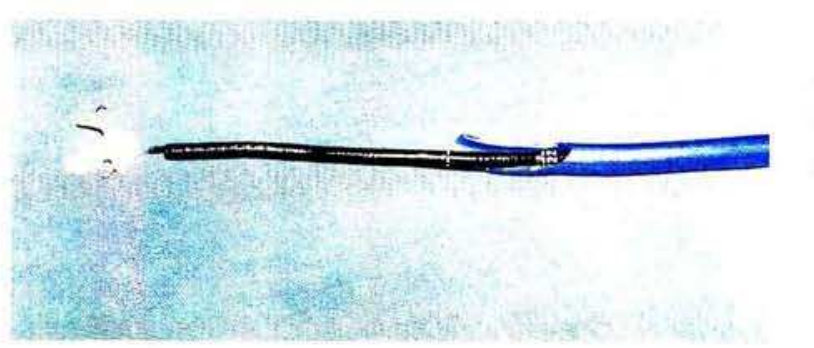

Figure 1: A mounted bevelied tube over the gastroscope. The denture is held in a polypectomy snare.

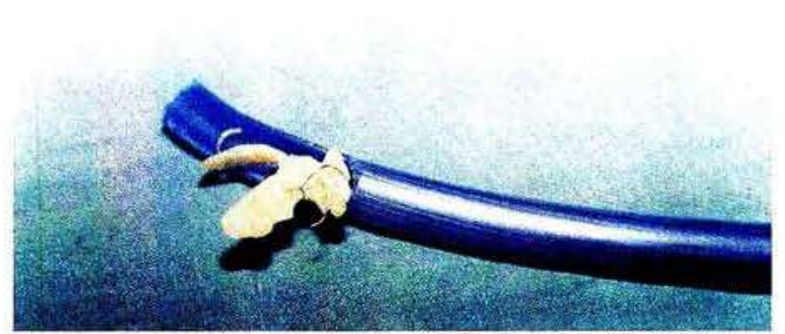

Figure 2: The mounted tube on the gastroscope has been moved beyond the gastroscope in such a way that the sharp hooks of the denture are in apposition to the bevelled end.

\section{Reference}

1. Cotton PB, Williams CB. Practical gastrointestinal endoscopy. Oxford: Blackwell Scientific. 1990.
Corresponding Author

S. P. Chouhan, M.D., M.S.

A-3, PBM Hospital Campus

Bikaner

Rajasthan 334001

India

Fax: +91-151-523764 